\title{
Comparison of B chromosome effects on Secale cereale and Secale vavilovii
}

\author{
M. J. Puertas, F. Romera and \\ A. de la Peña
}

\begin{abstract}
Departamento de Genetica, Facultad de Biología,
\end{abstract} Universidad Complutense, Madrid 28040, Spain

B chromosomes of $S$. cereale have been introduced into $S$. vavilovii, which lacks them in nature, to compare their effects on fitness. In both species, viability was unaffected, while fertility progressively decreased when the number of $B$ chromosomes increased from two to four. These effects depend on the $B$ chromosome number of the individuals, and not on the frequency of $B$ chromosomes in the population.

From the similarity of $B$ chromosome effects on $S$. cereale and $S$. vavilovii it is argued that the maintenance of B chromosome polymorphisms mainly depends on $B$ chromosomes themselves, and not on a coadaptation between $B$ chromosomes and the cereale genome.

\section{INTRODUCTION}

B chromosomes produce deleterious effects on characters related to fertility (see Jones and Rees, 1982 for a review), especially if they are present in large numbers. B chromosomes are transmitted following non-Mendelian species-specific rules. In rye, they tend to increase in number during both male and female gametogenesis (Müntzing, 1946; Hakanson, 1948). Most authors believe that this tendency to accumulation would be enough to compensate for the selection against individuals carrying a high number of $\mathrm{B}$ chromosomes, maintaining B chromosome polymorphism in spite of the low fitness of carriers.

However, Kimura (1962) proposed that to maintain a high fitness the genetic load will tend to be reduced by making the effect of $\mathrm{B}$ chromosomes less deleterious through both evolutionary modification of the proper genotype by natural selection and loss in function of the supernumerary chromosome due to accumulation of amorphic mutations.

The relative importance of these two factors has been evaluated in the present paper by introducing B chromosomes from a species naturally carrying B chromosomes at high frequency (Secale cereale), into a closely related species lacking them $(S$. vavilovii), to see whether the introduction of Bs into the latter greatly influences its fitness or not. If the species that naturally lacks B chromosomes is strongly affected, a coadaptation between $\mathrm{B}$ chromosomes and the cereale genome probably accounts for the maintenance of B chromosome polymorphisms. Conversely, if it is not excessively affected, this indicates a relative inertness of $\mathrm{B}$ chromosomes.

\section{MATERIALS AND METHODS}

Rye, Secale cereale var. JNK, and $S$. vavilovii have been used, both $2 n=14$. 65 per cent of JNK individuals show $\mathrm{B}$ chromosomes. The mean number of B chromosomes per plant is 1.57. S. vavilovii does not naturally carry B chromosomes.

Both species behave as if rather closely related. They differ by three reciprocal translocations involving six chromosomes. The mean chiasma frequency of interspecific hybrids is about 11.9 , being 13.5 and 12.5 in $S$. cereale and $S$. vavilovii, respectively (Jain, 1960; Khush and Stebbins, 1961 ; Carmona and Puertas, 1977). They also differ in their mating system: $S$. cereale is a cross-pollinating species, while $S$. vavilovii is a self-pollinating one.

B chromosomes were introduced from $S$. cereale into $S$. vavilovii by hybridising both species and backcrossing to $S$. vavilovii during six successive generations (Carmona and Puertas, loc. cit.). Thus, true $S$. vavilovii with B chromosomes of $S$. cereale was obtained. This line has been named "Charito". 
Table 1 Different types of experimental populations established for $S$. cereale and $S$. vavilovii

\begin{tabular}{|c|c|c|c|c|}
\hline Species & Population & Plant $B$ number & Number of plants & Plant frequency \\
\hline S. cereale & Uniform & & & \\
\hline \multirow{15}{*}{ var. JNK } & 1 & $\mathrm{OB}$ & 29 & $1 \cdot 00$ \\
\hline & 2 & $1 \mathrm{~B}$ & 17 & $1 \cdot 00$ \\
\hline & 3 & $2 \mathrm{~B}$ & 41 & $1 \cdot 00$ \\
\hline & 4 & $3 B$ & 28 & 1.00 \\
\hline & 5 & $4 B$ & 27 & 1.00 \\
\hline & Mixed & & & \\
\hline & A & $\mathrm{OB}$ & 50 & 0.57 \\
\hline & & $2 B$ & 19 & 0.22 \\
\hline & & $4 B$ & 18 & 0.21 \\
\hline & B & $\mathrm{OB}$ & 20 & $0 \cdot 20$ \\
\hline & & $2 \mathrm{~B}$ & 58 & $0 \cdot 60$ \\
\hline & & $4 B$ & 20 & $0 \cdot 20$ \\
\hline & $C:$ & $\mathrm{OB}$ & 18 & 0.19 \\
\hline & & $2 \mathrm{~B}$ & 20 & 0.21 \\
\hline & & $4 B$ & 57 & $0 \cdot 60$ \\
\hline S. vavilovii & Uniform & & & \\
\hline \multirow[t]{11}{*}{ Charito line } & 1 & $0 \mathrm{~B}$ & 33 & $1 \cdot 00$ \\
\hline & 2 & $2 \mathrm{~B}$ & 23 & $1 \cdot 00$ \\
\hline & 3 & $3 B$ & 23 & 1.00 \\
\hline & 4 & $4 \mathrm{~B}$ & 27 & $1 \cdot 00$ \\
\hline & Mixed & & & \\
\hline & A & $\mathrm{OB}$ & 29 & 0.59 \\
\hline & & $2 B$ & 10 & $0 \cdot 20$ \\
\hline & & $4 B$ & 10 & 0.20 \\
\hline & $\mathrm{B}$ & OB & 10 & $0 \cdot 20$ \\
\hline & & $2 \mathrm{~B}$ & 10 & $0 \cdot 20$ \\
\hline & & $4 B$ & 30 & 0.60 \\
\hline
\end{tabular}

Two types of experimental populations were established for both species:

1. uniforms, in which all the plants within a population carried the same number of $B$ chromosomes

2. mixed, in which there were individuals with 0,2 and $4 \mathrm{~B}$ at different frequencies in each population.

The types of experimental populations, and the plant number of each one, are shown in table 1. Unfortunately, it was not possible to find enough plants to establish the same number of individuals per population.

Plants were simultaneously sown in adjacent $1 \mathrm{~m}^{2}$ plots in an experimental field. At the moment of anthesis each plot was covered with a thin white cotton fabric to prevent cross-pollination among plots, allowing open-pollination within each one.

Offspring were individually collected in order to count the number of spikes, flowers and seeds per plant. To estimate the percentage of seed germination, a sample of about 100 seeds per population was laid on a wet filter paper, and germination was defined as a shoot and root length of at least $1 \mathrm{~cm}$ after 5 days.
Chromosome counts were made in root tips. They were fixed in acetic-alcohol $1: 3$, and stained by the Feulgen method.

\section{RESULTS}

For each population the number of grains per plant $(G / P)$, grains per spike $(G / S)$, grains per flower $(G / F)$, flowers per plant $(F / P)$, flowers per spike $(\mathrm{F} / \mathrm{S})$, spikes per plant $(\mathrm{S} / \mathrm{P})$, and the percentage of germination $(\% \mathrm{G})$ was estimated.

Tables 2 and 3 show the results for JNK and Charito populations, respectively. It can be observed that in both cases the mean number of $G / P, G / S$, and $G / F$ decreases as the number of $\mathrm{B}$ chromosomes increases. On the other hand, the mean number of $F / P, F / S, S / P$ and $\% G$ remains constant irrespective of the $\mathrm{B}$ chromosome number of the individuals.

It has to be noted that $S$. cereale populations $A$ and C (table 2), which show a lower seed number than other populations, suffered an accidental bird attack because the cotton cover was removed few 
Table 2 Fertility and viability variables estimated in the different populations of Secale cereale

\begin{tabular}{|c|c|c|c|c|c|c|c|c|}
\hline \multicolumn{2}{|c|}{ Populations } & $G / P$ & $\mathrm{G} / \mathrm{S}$ & $\mathrm{G} / \mathrm{F}$ & $\mathrm{F} / \mathrm{P}$ & $F / S$ & $\mathrm{~S} / \mathrm{P}$ & $\% \mathrm{G}$ \\
\hline \multicolumn{9}{|c|}{ Uniforms } \\
\hline & $\mathrm{OB}$ & $42 \cdot 51$ & $17 \cdot 13$ & 0.37 & $115 \cdot 52$ & $46 \cdot 53$ & $2 \cdot 48$ & 88 \\
\hline & $1 \mathrm{~B}$ & $51 \cdot 88$ & $13 \cdot 16$ & 0.34 & $151 \cdot 18$ & $38 \cdot 36$ & $3 \cdot 94$ & 86 \\
\hline & $2 \mathrm{~B}$ & $25 \cdot 73$ & $8 \cdot 24$ & 0.21 & $124 \cdot 83$ & 39.98 & $3 \cdot 12$ & 85 \\
\hline & $3 \mathrm{~B}$ & $15 \cdot 89$ & $5 \cdot 11$ & 0.11 & $142 \cdot 64$ & $45 \cdot 90$ & $3 \cdot 11$ & 86 \\
\hline & $4 B$ & $8 \cdot 85$ & $2 \cdot 78$ & 0.06 & $141 \cdot 85$ & $46 \cdot 67$ & $3 \cdot 19$ & 78 \\
\hline \multicolumn{9}{|c|}{ Mixed } \\
\hline & $\mathrm{OB}$ & $11 \cdot 28$ & $6 \cdot 56$ & $0 \cdot 14$ & $83 \cdot 36$ & $48 \cdot 47$ & $1 \cdot 72$ & 82 \\
\hline \multirow[t]{3}{*}{ A } & $2 \mathrm{~B}$ & $4 \cdot 16$ & $2 \cdot 82$ & 0.07 & $63 \cdot 05$ & $49 \cdot 79$ & $1 \cdot 47$ & 85 \\
\hline & $4 B$ & $2 \cdot 22$ & $1 \cdot 33$ & 0.03 & $66 \cdot 89$ & $40 \cdot 13$ & $1 \cdot 67$ & 79 \\
\hline & $\mathrm{OB}$ & $45 \cdot 90$ & $19 \cdot 96$ & 0.51 & $89 \cdot 70$ & $39 \cdot 00$ & $2 \cdot 30$ & 80 \\
\hline \multirow[t]{3}{*}{ B } & $2 \mathrm{~B}$ & $32 \cdot 59$ & $13 \cdot 60$ & 0.32 & $102 \cdot 53$ & $42 \cdot 78$ & $2 \cdot 40$ & 80 \\
\hline & $4 B$ & $7 \cdot 55$ & $2 \cdot 96$ & 0.07 & $101 \cdot 40$ & $39 \cdot 76$ & $2 \cdot 55$ & 71 \\
\hline & $\mathrm{OB}$ & $14 \cdot 33$ & $7 \cdot 17$ & $0 \cdot 20$ & $70 \cdot 22$ & $35 \cdot 11$ & $2 \cdot 00$ & 82 \\
\hline \multirow[t]{2}{*}{$\mathrm{C}$} & $2 \mathrm{~B}$ & $7 \cdot 85$ & $3 \cdot 74$ & $0 \cdot 11$ & $71 \cdot 50$ & $34 \cdot 05$ & $2 \cdot 10$ & 74 \\
\hline & $4 B$ & $7 \cdot 60$ & $2 \cdot 87$ & 0.07 & $106 \cdot 50$ & $40 \cdot 20$ & $2 \cdot 65$ & 78 \\
\hline
\end{tabular}

$\mathrm{G} / \mathrm{P}=$ Grains per plant. $\mathrm{G} / \mathrm{S}=\mathrm{Grains}$ per spike. $\mathrm{G} / \mathrm{F}=\mathrm{Grains}$ per flower.

$\mathrm{F} / \mathrm{P}=$ Flowers per plant. $\mathrm{F} / \mathrm{S}=$ Flowers per spike. $\mathrm{S} / \mathrm{P}=$ Spikes per plant.

$\% \mathrm{G}=$ Percentage of germination.

Table 3 Fertility and viability variables estimated in the different populations of Secale vavilovii

\begin{tabular}{|c|c|c|c|c|c|c|c|c|}
\hline \multicolumn{2}{|c|}{ Populations } & $\mathrm{G} / \mathrm{P}$ & $\mathrm{G} / \mathrm{S}$ & $\mathrm{G} / \mathrm{F}$ & $\mathrm{F} / \mathrm{P}$ & $\mathrm{F} / \mathrm{S}$ & $\mathrm{S} / \mathrm{P}$ & $\% \mathrm{G}$ \\
\hline \multicolumn{9}{|c|}{ Uniforms } \\
\hline & $\mathrm{OB}$ & $58 \cdot 30$ & $16 \cdot 73$ & 0.68 & $85 \cdot 88$ & $24 \cdot 64$ & 3.48 & 64 \\
\hline & $2 \mathrm{~B}$ & $42 \cdot 00$ & $12 \cdot 71$ & 0.54 & $78 \cdot 43$ & $23 \cdot 74$ & $3 \cdot 30$ & 77 \\
\hline & $3 \mathrm{~B}$ & $23 \cdot 35$ & $6 \cdot 71$ & 0.25 & $91 \cdot 91$ & $26 \cdot 42$ & $3 \cdot 48$ & 81 \\
\hline & $4 B$ & $6 \cdot 22$ & $1 \cdot 58$ & 0.06 & $111 \cdot 04$ & $28 \cdot 28$ & $3 \cdot 93$ & 71 \\
\hline \multicolumn{9}{|c|}{ Mixed } \\
\hline & OB & $52 \cdot 90$ & $14 \cdot 34$ & 0.57 & $92 \cdot 76$ & $25 \cdot 14$ & 3.69 & 80 \\
\hline \multirow[t]{3}{*}{ A } & $2 \mathrm{~B}$ & $26 \cdot 30$ & $7 \cdot 94$ & 0.35 & $80 \cdot 80$ & $24 \cdot 48$ & $3 \cdot 30$ & 72 \\
\hline & $4 \mathrm{~B}$ & $3 \cdot 50$ & 1.09 & 0.04 & $84 \cdot 40$ & $26 \cdot 38$ & $3 \cdot 20$ & 71 \\
\hline & $\mathrm{OB}$ & $50 \cdot 20$ & 22.68 & 0.54 & 93.00 & $22 \cdot 68$ & $4 \cdot 10$ & 70 \\
\hline \multirow[t]{2}{*}{ B } & 2B & $32 \cdot 90$ & $7 \cdot 00$ & $0 \cdot 37$ & $88 \cdot 20$ & $18 \cdot 77$ & $4 \cdot 70$ & 86 \\
\hline & $4 B$ & $7 \cdot 03$ & 1.39 & 0.06 & $108 \cdot 33$ & $21 \cdot 38$ & $5 \cdot 07$ & 65 \\
\hline
\end{tabular}

$\mathrm{G} / \mathrm{P}=$ Grains per plant. $\mathrm{G} / \mathrm{S}=\mathrm{Grains}$ per spike. $\mathrm{G} / \mathrm{F}=\mathrm{Grains}$ per flower.

$\mathrm{F} / \mathrm{P}=$ Flowers per plant. $\mathrm{F} / \mathrm{S}=$ Flowers per spike. $\mathrm{S} / \mathrm{P}=$ Spikes per plant.

$\% \mathrm{G}=$ Percentage of germination.

days before harvesting. Therefore, these populations were not included in the statistical analyses.

One way analyses of variance were made to compare the mean values obtained for the main variables of fertility and viability $(G / P$ and $F / P$, respectively). Their variation was considered in relation to :

1. the number of $\mathrm{B}$ chromosomes: comparisons among plants with different number of $\mathrm{B}$ chromosomes considering separately the uniform and mixed populations,

2. population frequencies: comparisons among groups of plants with the same B chromosome number belonging both to uniform and mixed populations.

Table 4 shows a summary of all the analyses of variance made. Detailed statistical data are not included, we only show the results of the F tests. In this table it can be observed that in all cases the mean number of $\mathrm{G} / \mathrm{P}$ was significantly different with respect to $\mathrm{B}$ chromosome number of the plants considered, both for $S$. cereale and $S$. vavilovii. However, when the source of variation was the population frequency, the differences for $G / P$ were not significant. 
Table 4 Summary of all ANOVAs made. The source of variation was either the number of B chromosomes or the population frequencies, for both $S$. cereale and $S$. vavilovii, considering the variables $G / P$ (fertility) and $F / P$ (viability).

\begin{tabular}{|c|c|c|c|c|}
\hline Species & Variable & Source of variation & Population & $\begin{array}{l}\text { Level of } \\
\text { significance }\end{array}$ \\
\hline $\begin{array}{l}S . \text { cereale } \\
\text { var. JNK }\end{array}$ & $G / P$ & Population freq. & $\begin{array}{l}\text { Uniforms } \\
\text { A mixed } \\
B \text { mixed } \\
C \text { mixed } \\
\text { Uniform (0B) and } 0 B \text { plants } \\
\text { from B mixed } \\
\text { Uniform (2B) and 2B plants } \\
\text { from B mixed } \\
\text { Uniform (4B) and 4B plants } \\
\text { from B mixed }\end{array}$ & $\begin{array}{l}* * * \\
* \\
* * * \\
* \\
\text { n.s. } \\
\text { n.s. } \\
\text { n.s. }\end{array}$ \\
\hline & $F / P$ & $\begin{array}{l}\text { Number of Bs } \\
\text { Population freq. }\end{array}$ & $\begin{array}{l}\text { Uniforms } \\
\text { A mixed } \\
B \text { mixed } \\
\text { C mixed } \\
\text { Uniform (0B) and } 0 B \text { plants } \\
\text { from B mixed } \\
\text { Uniform (2B) and 2B plants } \\
\text { from B mixed } \\
\text { Uniform (4B) and 4B plants } \\
\text { from B mixed }\end{array}$ & $\begin{array}{l}\text { n.s. } \\
\text { n.s. } \\
\text { n.s. } \\
* \\
\text { n.s. } \\
\text { n.s. } \\
*\end{array}$ \\
\hline $\begin{array}{l}\text { S. vavilovii } \\
\text { Charito line }\end{array}$ & $\mathrm{G} / \mathrm{P}$ & $\begin{array}{l}\text { Number of Bs } \\
\text { Population freq. }\end{array}$ & $\begin{array}{l}\text { Uniforms } \\
\text { A mixed } \\
\text { B mixed } \\
\text { Uniform (0B) and 0B plants } \\
\text { from A and B mixed } \\
\text { Uniform (2B) and 2B plants } \\
\text { from A and B mixed } \\
\text { Uniform (4B) and 4B plants } \\
\text { from A and B mixed } \\
\text { Uniforms } \\
\text { A mixed } \\
\text { B mixed } \\
\text { Uniform (0B) and 0B plants } \\
\text { from A and B mixed } \\
\text { Uniform (2B) and 2B plants } \\
\text { from A and B mixed } \\
\text { Uniform (4B) and 4B plants } \\
\text { from A and B mixed }\end{array}$ & $\begin{array}{l}* * * \\
* * * \\
* * * \\
\text { n.s. } \\
\text { n.s. } \\
\text { n.s. } \\
\text { n.s. } \\
\text { n.s. } \\
\text { n.s. } \\
\text { n.s. } \\
\text { n.s. } \\
* * *\end{array}$ \\
\hline
\end{tabular}

*significance at 5 per cent. $\mathrm{G} / \mathrm{P}=$ grains per plant.

*** significant at 1 per cent or lower. $\mathrm{F} / \mathrm{P}=$ flowers per plant. n.s. non significant.

When the variable analysed was $F / P$, the analyses of variance were non-significant in most cases, both with respect to $\mathrm{B}$ chromosome number and to population frequencies.

In addition, correlation coefficients were calculated for two purposes:

1. to establish the relation of variables estimating fertility with respect to $\mathrm{B}$ chromosome number. Calculations were made considering all individuals from the different populations as a whole. The results are shown in table 5 .
Correlation coefficients for variables estimating viability were not calculated, since analyses of variance adequately demonstrated that viability does not vary with respect to $\mathrm{B}$ chromosome number.

2. To compare the main component of fertility $(\mathrm{G} / \mathrm{P})$ in $S$. cereale and $S$. vavilovii (table 5 ).

Also, regression coefficients were calculated between the variables number of B chromosomes and $\mathrm{G} / \mathrm{P}$, both for $S$. cereale and $S$. vavilovii (table $5)$. Differences between regression coefficients were in neither case significant $(t=0.26, P>0.5)$. 
Table 5 Correlation and regression coefficients for the variables estimating fertility

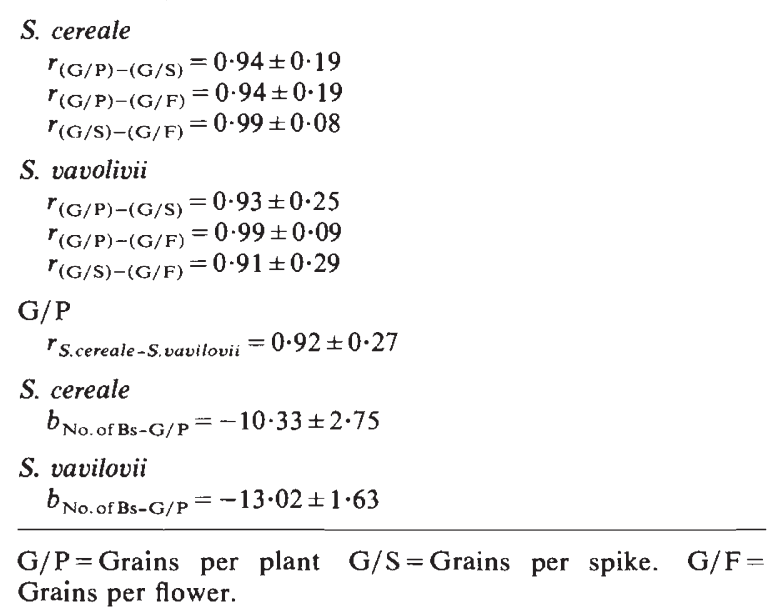

\section{DISCUSSION}

Our results indicate that estimations of viability by the mean number of $F / P, F / S, S / P$ and $\% G$ do not depend on the number of $\mathrm{B}$ chromosomes of the individuals, in $S$. cereale nor in $S$. vavilovii, in uniform or mixed populations. Analyses of variance to compare the values of viability with respect to the $\mathrm{B}$ chromosome number were made only for the variable F/P. We consider that it is not necessary to make ANOVAs for the other variables since they remain clearly constant (see tables 2 and 3 ), that is, they do not vary when the number of $\mathrm{B}$ chromosomes varies. This result agrees with estimations made by Müntzing (1967) with Korean rye varieties. However, in other cases a decrease in vegetative form with the increase of B chromosome number has been reported (Müntzing, 1963; Kishikawa, 1965).

We consider that unmodified viability with respect to $\mathrm{B}$ chromosome number is consistent with the idea of compensation between the accumulation mechanism and the load imposed by $B$ chromosomes. Polymorphism would be maintained if plants with a high number of $B$ chromosomes produce sufficient pollen but a reduced number of offspring.

It has to be noted that plants with $4 \mathrm{~B}$ chromosomes have a number of $\mathrm{S} / \mathrm{P}$ and $\mathrm{F} / \mathrm{P}$ slightly higher than other constitutions, which resulted in significant differences in mixed population $\mathrm{C}$ of $S$. cereale (tables 2 and 5). Probably, 4B plants which show the lowest fertility do not use much energy for seed formation, and they use the remaining energy for forming late tillers which were always sterile.

The observed values of variables estimating fertility (G/P, G/S, G/F) progressively decrease when the number of $\mathrm{B}$ chromosomes increases (tables 2 and 3). This result has been obtained repeatedly (Müntzing, 1963; 1967; Moss, 1966). In other cases, a zig-zag effect corresponding with odd and even number of B chromosomes was reported. In our experiment, the effect of $B$ chromosomes seems to be cumulative.

The ANOVAs made to compare the mean number of $G / P$ with respect to the number of $B$ chromosomes were significant in all cases. The ANOVAs for $G / S$ and $G / F$ were not performed since their correlation coefficients with respect to $G / P$ gave 0.94 in both cases, indicating that the three variables vary similarly with respect to the number of B chromosomes.

It would be possible that the average number of $\mathrm{B}$ chromosomes in a population could influence the plant fitness. For example, it would be possible that $4 \mathrm{~B}$ plants produced few offspring when their frequency was high, and more offspring when it was low.

To test this possibility mixed populations with $0 \mathrm{~B}, 2 \mathrm{~B}$ and $4 \mathrm{~B}$ plants at different frequencies were established. The results obtained showed that the fitness of the individuals depend on their own number of $\mathrm{B}$ chromosomes, irrespective of the companion plants of the same population. The mean number of $G / P$ and $F / P$ did not differ significantly among plants with the same $\mathrm{B}$ chromosome number belonging to different populations, mixed or uniform, both in $S$. cereale and $S$. vavilovii (table 4).

The main purpose of this work was to compare the effect of B chromosomes on $S$. cereale and $S$. vavilovii. The regression coefficients between the number of B chromosomes and G/P in $S$. cereale and $S$. vavilovii were not significantly different, demonstrating that the decrease of fertility with the increase of the number of B chromosomes is similar in both species.

A correlation coefficient was calculated between species for the variable $G / P$ with respect to the $\mathrm{B}$ chromosome number. The result $(r=0.92)$ also demonstrates that this variable varies similarly in both species.

It can, therefore, be deduced that B chromosomes affect fitness irrespective of the genome of the carriers tested. A genetic coadaptation between $\mathrm{B}$ chromosomes and the cereale genome seems not to be the main cause for the maintenance of $B$ chromosome polymorphisms. On Kimura's 
hypothesis (loc. cit.) a relative inertness would account for their maintenance. However, the data obtained in the present work show that plants with 2,3 or $4 \mathrm{~B}$ are individually strong but their fertility is progressively affected, while plants with $1 \mathrm{~B}$ give more descendants than $0 \mathrm{~B}$ plants. These results indicate that $\mathrm{B}$ chromosomes are not inert. Therefore, it seems that the maintenance of B chromosome polymorphisms depends mainly on the B chromosomes themselves.

Our results are in agreement with the proposal of Matthews and Jones $(1982 ; 1983)$ that B chromosomes are of a "selfish" nature. Their cytological mechanism of accumulation will be compensated by the relatively low fitness of plants with high numbers. Their cumulative deleterious effects provide a mechanism preventing an excessive increase.

Acknowledgements The $S$. vavilovii line carrying B chromosomes was named "Charito" in memory of our colleague Charo Carmona unfortunately deceased.

This work has been supported by a grant of the Comision Asesora de Investigaciòn Cientifica y Tècnica of Spain.

\section{REFERENCES}

CARMONA, R. ANI) PUERTAS, M. J. 1977. Absence of qualitative genes controlling interspecific pairing in rye $\mathrm{B}$ chromosomes. Theor. Appl. Genet., 51, 111-117.
HAKANSON. A. 1948. Behaviour of accessory chromosomes in embryo-sac Hereditas, 34, 35-59.

JAIN, S. K. 1960. Cytogenetics of rye (Secale sp.). BibliographiaGenetica 29, 1-86.

JONES, R. N. ANI) REES, H. 1982. B chromosomes, Academic Press, NewYork.

KHUSH, G. S. AND STEBBINS, (i. L. 1961. Cytogenetic and evolutionary studies in Secale 1. Some new data of the ancestry of $S$. cereale Amer. J. Bot., 48, 723-730.

KIMURA, M. 1962, A suggestion on the experimental approach to the origin of supernumerary chromosomes. The American Naturalist, XCVI, 319-320.

KISHIKAWA, H. 1965. Cytogenetic studies of B chromosomes in rye, Secale cereale in Japan. Agr. Bul. Saga. Univ., 21, $1-81$.

MATTHEWS, R. B. AND JONI:S, R. N. 1982. Dynamics of the B chromosomes polymorphism in rye I. Simulated populations. Heredity, 48, 345-369.

MATHEWS, R. B. AND JONES, R. N. 1983. Dynamics of the B chromosome polymorphism in rye II. Estimates of parameters. Heredity, 50, 119-137.

MOSS, J. P. 1966. The adaptive significance of B chromosomes in rye. Chromosomes Today, 1, 15-25.

MÜNTZING, A. 1946. Cytological studies of extra fragment chromosomes in rye III. The mechanism of non-disjunction at the pollen mitosis. Hereditas, 32, 507-509.

MÜNTZING, A. 1963. Effects of accessory chromosomes in diploid and tetraploid rye. Hereditas, 49, 361-426.

MÜNTZING, A. 1967. Some main results from investigations on accessory chromosomes. Heredilas, 57, 432-438. 